\title{
Morphological Effects of Argon Laser Trabeculoplasty upon the Glaucomatous Human Meshwork
}

\author{
R. A. ALEXANDER and I. GRIERSON \\ London
}

\begin{abstract}
Summary
Thirty four trabeculectomy specimens from open angle glaucoma patients who had under argon laser trabeculoplasty as part of their treatment, were studied by scanning electron microscopy. Three of these were also examined by transmission electron microscopy. The intervals between laser therapy and surgery ranged from one month to five years. A sub-group consisted of six patients who had received laser treatment on more than one occasion prior to surgery. Electron microscopy revealed distortion of trabecular beams, loss of trabecular endothelial cells and the development of a cellular sheet extending from the region of Schwalbe's line and covering the anterior surfaces of the anterior portion of the uveal meshwork. The sheet occluded the trabecular spaces of the region; thus, when extensive, contributing to laser trabeculoplasty failure. It is concluded that argon laser trabeculoplasty induces a repair process, in the form of repopulating a cellular deficient meshwork, but which can become detrimental as a consequence of its success.
\end{abstract}

The argon laser trabeculoplasty (ALT) method of Wise and Witter ${ }^{1}$ has been shown to be successful in lowering the intraocular pressure of a high percentage of chronic open angle glaucoma patients. ${ }^{2,3}$ ALT can defer surgery for the remaining lifespan of elderly patients and has controlled open angle glaucoma in others for over 10 years. ${ }^{4}$ Unfortunately the beneficial intraocular pressure lowering effects of ALT may be superceded in the course of time to the extent that trabeculectomy is required.,

The means by which ALT produces the clinically observed decrease in pressure has been accounted for by both mechanical changes to the trabecular beams ${ }^{1,5}$ and active cellular mechanisms. ${ }^{6,7}$ Rodrigues et $a{ }^{6}{ }^{6}$ described the ultrastructural changes induced by ALT in 22 trabeculectomy specimens obtained from six weeks to one year post treatment. Weber et al. ${ }^{5}$ studied three similar specimens taken two to eight months post ALT but with conflicting results. Specifically, Weber et al. ${ }^{5}$ did not observe the intratrabecular-space-occluding cellular sheet that was a feature of Rodrigues et al. ${ }^{6}$ These specimens may be considered to represent failed ALT. It is the purpose of this communication to present our own cases (34) of ALT failure, in the hope that by elucidating the pathology of failure one may be able to more fully understand the cellular responses evoked by ALT and to reconcile the different findings of Rodrigues ${ }^{6}$ and Weber ${ }^{5}$ by virtue of being a third report.

\section{Materials and methods}

Thirty-four trabeculectomy specimens were available for study from eyes that had received 
Table I The cases studied

\begin{tabular}{|c|c|c|c|}
\hline Case & Time post $A L T$ & $\begin{array}{l}\text { Cell sheets } \\
(\text { coronal } \times \text { advance } \mu \mathrm{m})\end{array}$ & $\begin{array}{l}\text { Speciment length* } \\
(\text { coronal } \mu \mathrm{m})\end{array}$ \\
\hline 1 & $4 W$ & negligible & 2050 \\
\hline 2 & $1 \mathrm{M}$ & $300 \times 400$ & 1900 \\
\hline 3 & $1 \mathrm{M}$ & $120 \times 50$ & 1400 \\
\hline 4 & $1 \mathrm{M}$ & negligible & 1200 \\
\hline 5 & $1 \mathrm{M}$ & $100 \times 100$ & 1700 \\
\hline 6 & $2 \mathrm{M}$ & $350 \times 250$ & 2050 \\
\hline 7 & $2 \mathrm{M}$ & negligible & 1500 \\
\hline 8 & $4 \mathrm{M}$ & $250 \times 150$ & 1700 \\
\hline 9 & $7 \mathrm{M}$ & $500 \times 300$ & 1700 \\
\hline 10 & $8 \mathrm{M}$ & $1000 \times 200$ & 1800 \\
\hline 11 & $9 \mathrm{M}$ & $300 \times 300$ & 1500 \\
\hline 12 & $9 \mathrm{M}$ & $375 \times 60$ & 1250 \\
\hline 13 & $10 \mathrm{M}$ & $200 \times 200$ & 1600 \\
\hline 14 & $11 \mathrm{M}$ & $700 \times 350$ & 1900 \\
\hline 15 & $1 \mathrm{Y} 1 \mathrm{M}$ & $150 \times 150$ & 1300 \\
\hline 16 & $1 \mathrm{Y} 1 \mathrm{M}$ & $250 \times 200$ & 2600 \\
\hline 17 & $1 \mathrm{Y} 2 \mathrm{M}$ & $350 \times 200 \& 200 \times 200$ & 1400 \\
\hline 18 & $1+Y$ & $150 \times 150$ & 2200 \\
\hline 19 & $2 \mathrm{Y} 1 \mathrm{M}$ & $300 \times 250$ & 2500 \\
\hline 20 & $2 \mathrm{Y} 2 \mathrm{M}$ & $1500 \times 300$ & 2250 \\
\hline 21 & $2 \mathrm{Y} 6 \mathrm{M}$ & $250 \times 150$ & 1900 \\
\hline 22 & $3 \mathrm{Y}$ & $150 \times 200$ & 3300 \\
\hline 23 & $3 \mathrm{Y} 9 \mathrm{M}$ & $350 \times 300 \& 300 \times 300$ & 3750 \\
\hline 24 & $4 Y$ & $250 \times 200$ & 3750 \\
\hline 25 & $5 Y$ & $250 \times 250 \& 400 \times 400$ & 2150 \\
\hline 26 & $?$ & negligible & 1800 \\
\hline 27 & $?$ & $150 \times 150$ & 1800 \\
\hline 28 & $?$ & $200 \times 200$ & 2150 \\
\hline 29 & $2 \mathrm{M}$ and $1 \mathrm{M}$ & $100 \times 50 \& 100 \times 100$ & 1650 \\
\hline 30 & $1+Y$ and $1 Y$ & $2000 \times 600$ & 2050 \\
\hline 31 & $2 \mathrm{Y}$ and $1 \mathrm{Y} 7 \mathrm{M}$ & $150 \times 100 \& 90 \times 100$ & 2700 \\
\hline 32 & $3 \mathrm{Y}, 2 \mathrm{Y}$ and $4 \mathrm{~W}$ & $400 \times 300 \& 120 \times 250$ & 1600 \\
\hline 33 & $1 \mathrm{Y} 10 \mathrm{M}, 5 \mathrm{M}$ and $3 \mathrm{M}$ & $200 \times 200 \& 150 \times 200$ & 2900 \\
\hline 34 & $1 \mathrm{Y} 9 \mathrm{M}, 1 \mathrm{Y}, 4 \mathrm{M}$ and $2 \mathrm{M}$ & $500 \times 300$ & 2150 \\
\hline
\end{tabular}

* Largest measurement of trabecular meshwork in the direction parallel to Schwalbe's line.

argon laser trabeculoplasty at some time in the course of treatment for chronic open angle glaucoma. The ALT procedure was performed by nine different surgeons, including: Mr. P. G. Watson (Cambridge, ten cases); Mr. E. D. Allen (Sunderland, nine cases); Mr. S. N. Rizk (Nottingham, five cases); Mr. R. A. Hitchings (London, three cases) and Mr. R. Bates (London, two cases). Technical information concerning the laser procedure and clinical details covering changes in IOP were not available in all instances. When described the ALT procedure closely followed that of Wise and Witter. ${ }^{1}$ At the time of surgery the patients' ages ranged from 43 to 83 years. Table I outlines the number of cases studied with respect to the time ALT was performed prior to trabeculectomy.

Trabeculectomy specimens were fixed by immersion in buffered glutaraldehyde for at least 24 hours, followed by buffered osmium tetroxide for 1.5 hours. Each specimen was dehydrated through ascending concentrations of ethanol prior to critical point drying and coating with gold. The inner surfaces of the trabecular meshwork and peripheral cornea were studied using an Hitachi S520 scanning electron microscope. Transmission electron 
microscopy of Araldite embedded material was performed on three cases andstudied using a Jeol 100C electron microscope.

\section{Results}

The most obvious abnormality of the inner surface of 30 out of the 34 trabeculectomy specimens was the presence of cellular sheets (Fig. 1) which encroached upon the anterior uveal meshwork, either 'advancing towards' or covering presumed laser impact sites. Smaller versions of the cellular sheets (wave fronts) were seen as significant irregularities in the outline of the corneal transitional zone endothelium. Both the larger cellular sheets and the smaller wave fronts were seen as continuations of theperipheral corneal endothelium. Table I relates the size of the trabeculectomy tissue and the dimensions of the cell sheets for each of the specimens studied.

\section{One treatment with $A L T$}

The one to five month post ALT group exhibited wave fronts or sheets which ranged in size from small $120 \mu \mathrm{m}$ (wide, coronal) by $50 \mu \mathrm{m}$ (advance, antero-posterior) to medium $300 \times 400 \mu \mathrm{m}$.

All measurements are approximated as the cellular sheets are not regular rectangles and

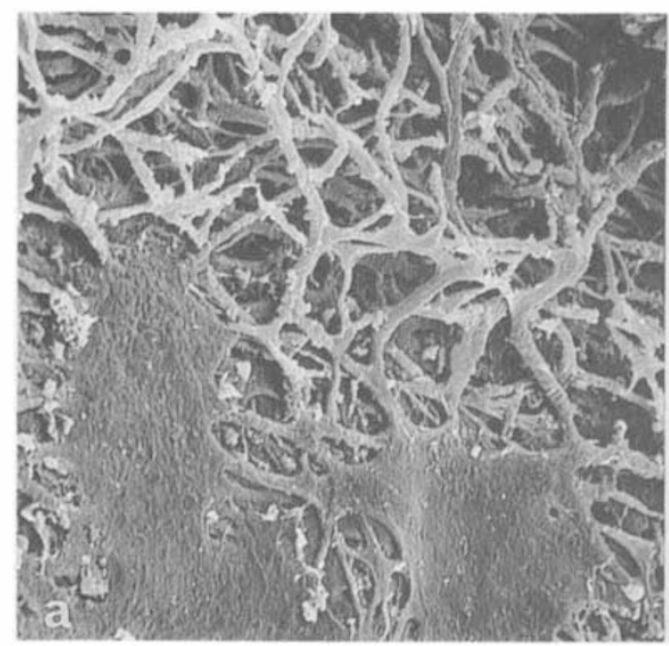

Fig. 1a. Scanning electron micrograph showing two small endothelial sheets covering areas of the anterior uveal meshwork. One of the sheets is seen to overlie a shallow depression. (24 and 19 months post ALT, $\times 350)$. in some instances the exact termination of the peripheral cornea was unclear. The seven to 14 month post laser group displayed similar sheets but which were generally larger in one or more directions (Fig. 2). Examples ranged from $150 \times 150 \mu \mathrm{m}$ to $700 \times 350 \mu \mathrm{m}$ and $1000 \times 200 \mu \mathrm{m}$. This larger response, which occluded a large amount of intratrabecular space, may correspond to an amalgamation of individual wave fronts or sheets. In the two to five year post ALT group there did not appear to be a correlation between size of sheet and time following laser treatment; since the largest sheet, measuring $1500 \times 300 \mu \mathrm{m}$, was present in a two year two month post ALT specimen (Fig. 3). Whereas the case obtained five years after treatment exhibited a sheet only $250 \times 250 \mu \mathrm{m}$ in size. Transmission electron microscopy (Fig. 4) revealed that the occluding sheet and wave fronts were formed by a monolayer of cells which were continuous with those of the transitional zone endothelium.

In two cases, the cellular sheets were seen beneath the most superficial trabecular beams rather than over. In four instances, ranging from one to two months and an unknown time post ALT, no cellular sheet or wave front was conclusively identified.

Many of the cells forming the sheets, in

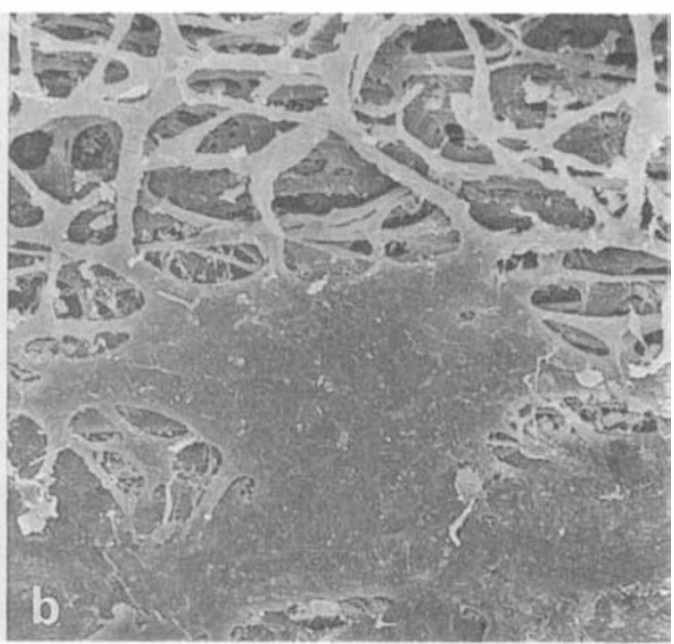

Fig. 1b. The small, intratrabecular space occluding, sheet is $150 \mu \mathrm{m}$ wide $\times 100 \mu \mathrm{m}$ advance over the meshwork. It is seen to be continuous with the transitional zone endothelium. (24 and 19 months post $A L T, \times 400)$. 


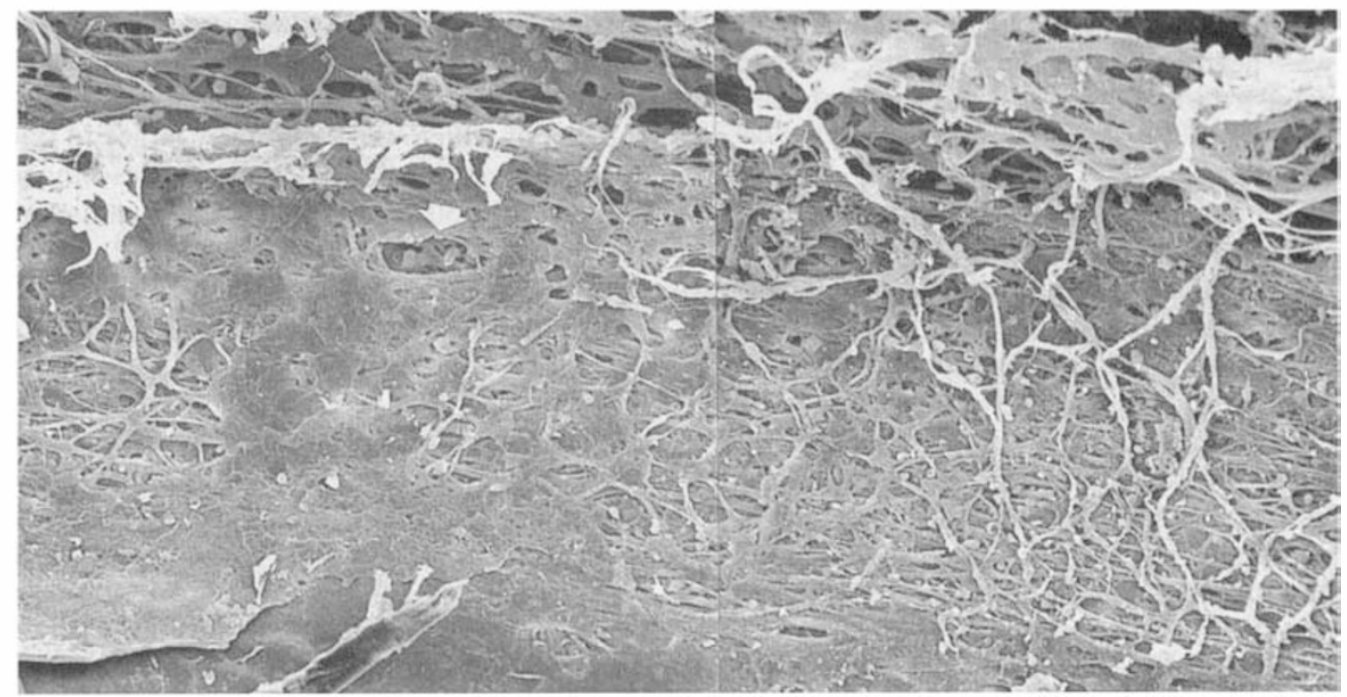

Fig. 2. Low magnification montage showing a $350 \times 200 \mu \mathrm{m}$ cellular sheet encompassing on $50 \mu \mathrm{m}$ hole (arrow). An inflammatory response is noted. (1y2m post $A L T, \times 210)$.

common with a number of corneal transitional endothelial cells appeared activated, in that they exhibited numerous small microvillilike surface processes (Figs. 4 and 5).

Some trabeculae at the margins of the occluding sheet (Fig. 6) or seen through deficiencies in the cellular cover were observed to be broken or distorted. Many were also seen to lack an enveloping endothelium (Fig. 7). A localised combination of distorted and denuded trabeculae were interpreted as being associated with the site of laser impact. The loss of trabecular cells resulted in connective tissue components becoming less compact, so causing the beams to appear thickened. A small number of surviving trabecular endo-

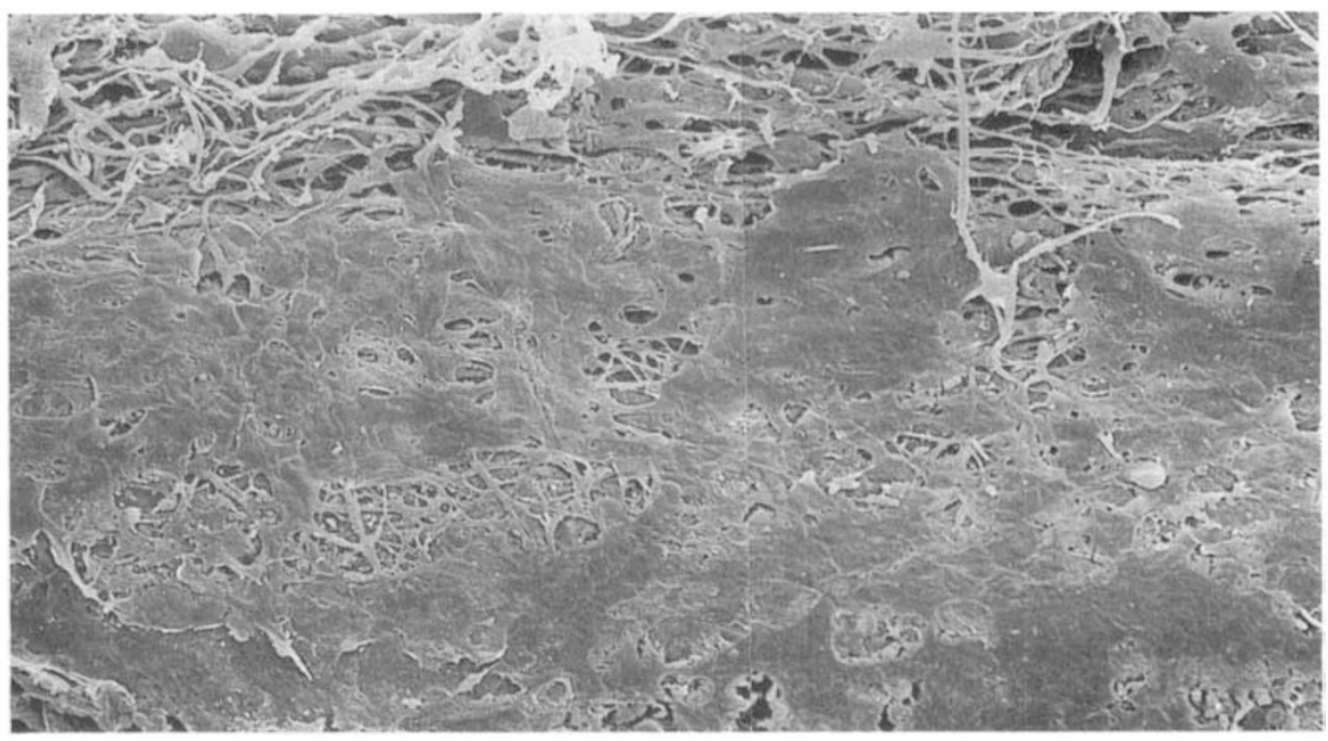

Fig. 3. Low power montage showing extensive coverage of the uveal meshwork by connected cellular sheets. Deficiencies in the sheet reveal trabecular beams. $(2 y 2 m$ post $A L T, \times 210)$. 


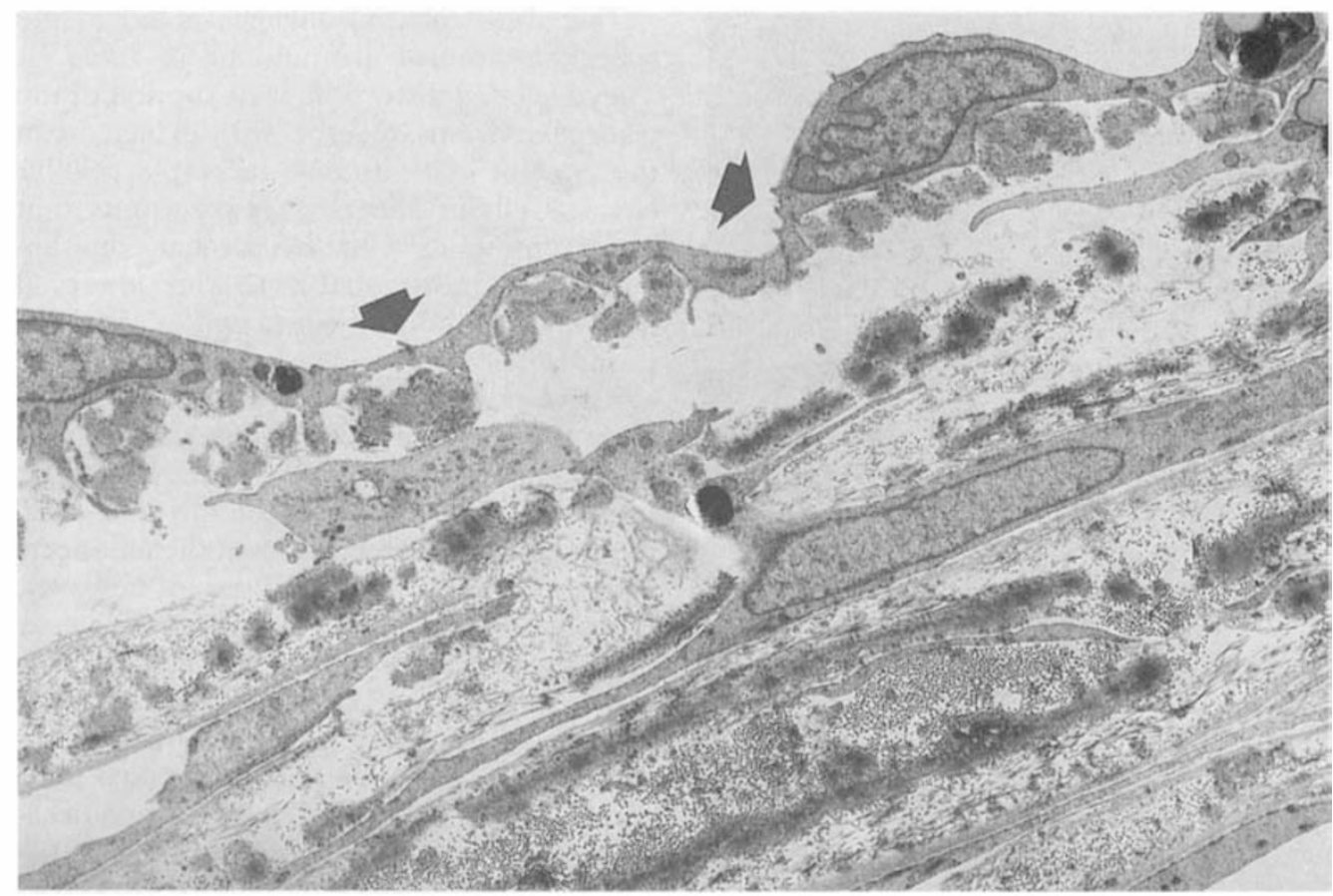

Fig. 4. Transmission electron micrograph showing the intratrabecular space occluding sheet to be formed by a cellular monolayer. Small microprocesses (arrows) are present. The deeper trabecular beams appear normal. (14m post $A L T, \times 6,600)$.

thelial cells around the laser impact site also exhibited signs of cellular activation. Six cases

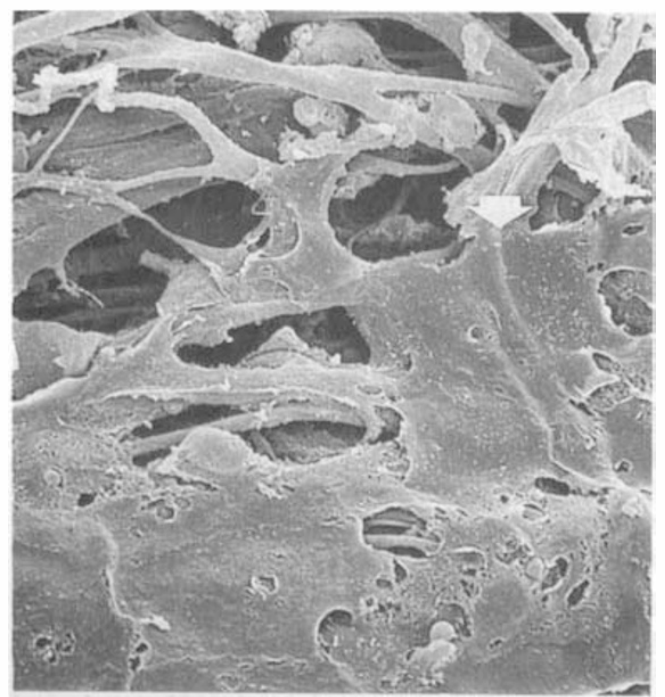

Fig. 5. The flat plate-like cells are shown to be occluding the intratrabecular spaces. Microprocesses are seen as mottling of the cell surface (arrowed cell). (2y $2 m$ post $A L T, \times 1,000)$. possessed a small number of long, thin migratory cells upon the corneal transitional en-

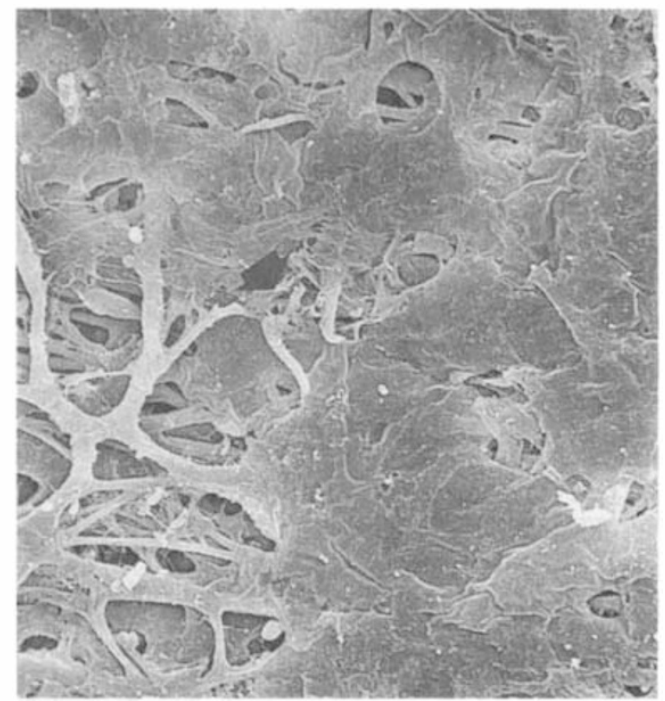

Fig. 6. Showing distorted trabeculae (arrow) at the lateral margin of a cellular sheet. (1y2m post ALT, $\times 600)$. 


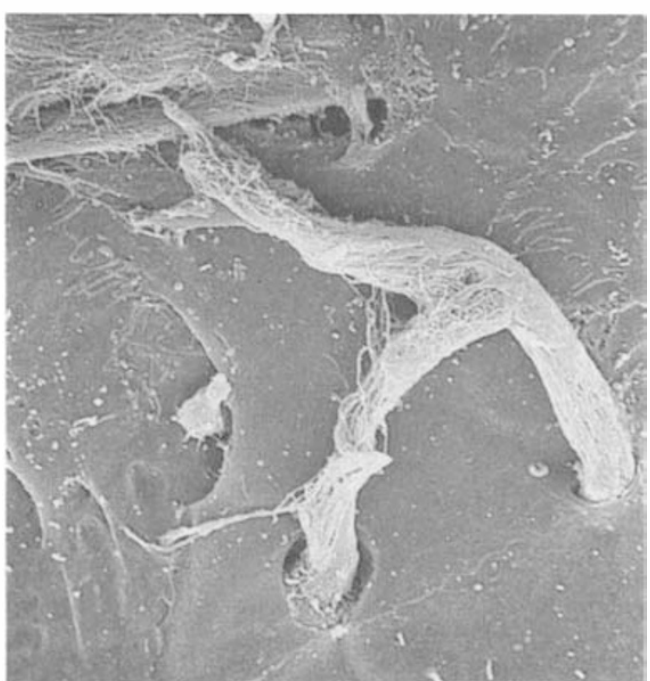

Fig. 7. Higher magnification of a broken trabeculum, protruding from an occluding sheet. The beam lacks an overlying endothelium. (2ylm post $A L T, \times 3,000)$.

dothelium. It was not possible to identify the direction of travel.

\section{Multiple treatment with ALT}

Six of the cases studied were of patients who had received ALT on two or more occasions prior to trabeculectomy. All of the specimens exhibited one or more intra trabecular spaceoccluding cellular sheets (Fig. 8) which were seen to be continuous with the endothelial cells of the transitional zone. The smallest individual sheet measured $100 \mu \mathrm{m}$ (wide) by 50 um (advance), whilst the largest was 2000 by $600 \mathrm{um}$ and covered most of the excised meshwork. As with the single treatment cases individual specimens displayed distorted and denuded trabeculae, cellular activation and cell migration. It was not possible to distinguish between older and more recent laser lesions.

\section{Discussion}

It has become apparent that the beneficial effect of ALT as a means of lowering the intraocular pressure is only temporary in some glaucoma patients. ${ }^{3}$ In the present study, trabeculectomy specimens were examined from eyes that had had their intraocular pressure controlled, following ALT, for up to five years before requiring surgery. A second group had received ALT on more than one occasion.
The ultrastructural changes noted in the specimens studied are outlined in Table II. They included distortion or disruption of the trabecular beams, together with an increase in the amount of trabeculae lacking a cellular cover. Cellular sheets or wave fronts that were continuous with the corneal endothelium of the transitional zone were observed partially or totally to cover and/or 'advance towards' the presumed laser impact site. The size and extent of the intratrabecular spaceoccluding sheet was not unequivocally related to the time interval between ALT and surgery. In general the one to five month post ALT group had less extensive endothelial sheets than the seven to 14 month group; however, exceptions were noted. The two to five year group was clearly not time related. The largest single cellular sheet observed, $2000 \mathrm{um}$ wide by $600 \mathrm{um}$ advance over the uveal meshwork, was present in a specimen taken from an eye that had received ALT on two occasions - one year and more than one yearprior to surgery. This is considered to represent an amalgamation of individual lesion wave fronts or sheets. Seven specimens possessed two completely separate cell sheets. The production of large or multiple cell sheets was not surgeon related.

The changes induced by ALT in human glaucomatous angular structures have been documented by Rodrigues' et al. ${ }^{6}$ (22 cases) and Weber et al. ${ }^{5}$ (three cases). Weber confirmed Rodrigues' observations of trabecular disruption and tissue debris formation but did not observe Rodrigues' finding of sheets of abnormal trabecular and/or corneal endothelial cells which covered the laser burns. We can confirm both Rodrigues' and Weber's observations since four or our cases did not exhibit a cellular sheet. In two of our cases the endothelial sheet was present beneath the most superficial beams of the uveal meshwork. The lack of an observed cellularsneet could also be a trabeculectomy sampling problem or that the laser impact site was in the posterior meshwork. Van der Zypen and Fankhauser ${ }^{8}$ studied the effect of ALT upon the monkey trabecular meshwork and concluded that it is advantageous to irradiate the posterior trabeculae so as to minimise corneal endothelial involvement. 


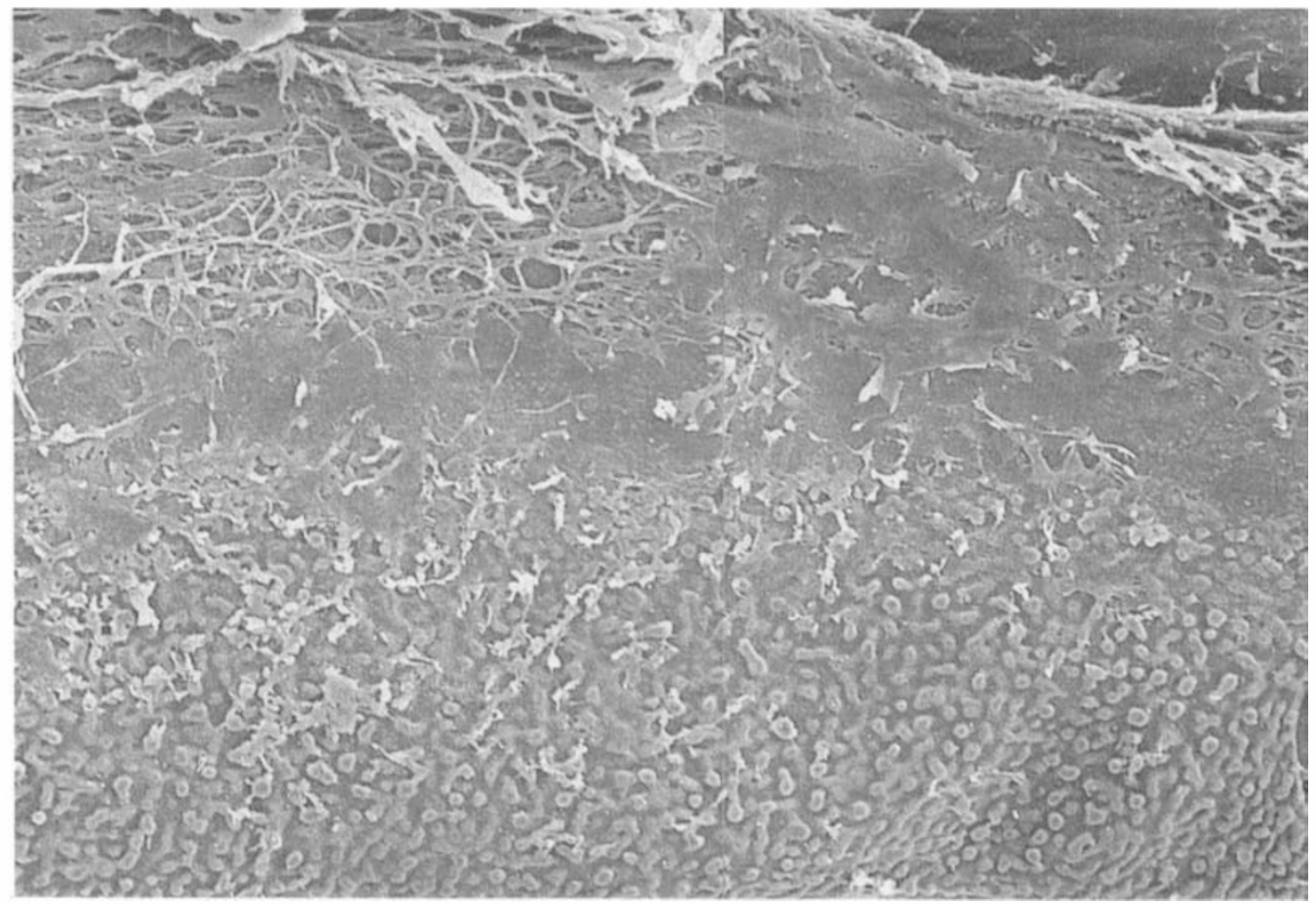

Fig. 8. Low power montage showing a $500 \times 300 \mu \mathrm{m}$ cell sheet. Note that the Hassal-Henle excrescences of the peripheral cornea lack a covering endothelium. $($ ALT $\times 4, \times 120)$.

The means by which ALT causes the clinically observed decrease in intraocular pressure in human glaucomatous eyes has not been established, other than that a direct communication between the uveal meshwork and Schlemm's canal is not required. ${ }^{1} \mathrm{Me}$ chanical, heat induced shrinkage of trabecular collagen has been suggested to cause the circumference of the meshwork to become smaller, move inwards and thus reopen the interbrabecular spaces. ${ }^{1,5}$ It is of interest that the temperature required to cause collagen to contract is increased when it is under tension. ${ }^{9}$ Bylsma et al.$^{10}$ argue against a purely mechanical reaction by commenting that the time course of ALT response is rather slow, whilst heat-induced shrinkage would be relatively quick.

The cellularity of the trabecular meshwork is known to be reduced as a consequence of normal ageing ${ }^{11,12}$ and with chronic open angle glaucoma. ${ }^{13,14}$ It has also been shown that trabecular endothelial cells are lost from the normal human trabecular meshwork when ALT is performed both in vivo before enu- cleation ${ }^{15}$ and in vitro upon donor eyes. ${ }^{7,16} \mathrm{We}$ suspect that ALT may cause a further loss of trabecular cells in glaucomatous eyes at and near the laser impact site as evidenced by the amount of denuded trabeculae observed. A significant increase in trabecular endothelial cell number has been noted within two days of in vitro ALT in human organ cultures. ${ }^{7,10}$ The proliferating cells ${ }^{7,10}$ are considered to be a specialised population that are located anterior to the filtering portion of the meshwork, ${ }^{16,17}$ at the corneal transitional zone. ${ }^{18}$ It has been suggested that these proliferating cells migrate to the laser impact site ${ }^{16}$ and perform the functions of normal trabecular endo-

Table II The effects of $A L T$

1. Trabecular endothelial cell death.

2. Distortion of trabecular beams.

3. Activation of surviving trabecular cells.

4. Activation/proliferation of transitional zone endothelial cells.

5. Wave front/cell sheet production.

6. Occlusion of laser impact site.

7. ? occlusion of meshwork. 
thelial cells such as phagocytosis and glycosaminoglycan production; both factors that are known to affect the rate of aqueous drainage. ${ }^{7}$ We did not observe evidence of cell division within the occluding sheet cells or at the transitional zone. However, we did observe cellular activation of surviving trabecular cells, sheet cells and transitional zone cells. Activation was seen as an increase in the amount of cellular surface processes. Trabecular endothelial cells are known to adopt an active form as a consequence of a number of insults, including tissue injury. ${ }^{18}$ The production of surface microprocesses by cultured meshwork cells has been shown to be a sign of phagocytic activity. ${ }^{19}$ As it has been suggested that the proliferating endothelial cells observed after ALT treatment might be phagocytic, ${ }^{7,10}$ then such stimulated cleaning function, if long lasting, could be involved with the success of ALT. However, when these cells are present in such numbers as to form the large confluent sheets seen in some of our cases, it could form a physical barrier to aqueous outflow. If this appearance is representative of the complete $360^{\circ}$ of the trabecular meshwork it must contribute to ALT failure. Thus we suggest that ALT can be considered to induce a repair mechanism, in the form of repopulating a cellular deficient meshwork but which ultimately becomes non-beneficial as a result of its success.

The authors would like to thank Mrs. P. Goodwin for secretarial assistance and Mr. Allen (Sunderland), Mr. Rizk (Nottingham) and Mr. Watson (Cambridge) for providing most of the specimens. Support has been provided by the International Glaucoma Association (IGA) and the Wellcome Trust.

\footnotetext{
References

${ }^{1}$ Wise JB and Witter SL: Argon laser therapy for open angle glaucoma. Arch Ophthalmol 1979, 97: 319-22.

${ }^{2}$ Wise JB: Long-term control of adult open angle glaucoma by argon laser treatment. Ophthalmology 1981, 88: 197-202.

${ }^{3}$ Grinich N, Van Buskirk EM, Samples JR: Three year efficacy of laser trabeculoplasty. Ophthalmology 1987, 94: 858-61

${ }^{4}$ Wise JB: Ten year results of laser trabeculoplasty.
}

Does the laser avoid glaucoma surgery or merely defer it? Eye 1987, 1: 45-50.

${ }^{5}$ Weber PA, Davidorf FH, McDonald C: Scanning electron microscopy of argon laser trabeculoplasty. Ophthalmic Forum 1983, 1: 26-9.

${ }^{6}$ Rodrigues MM, Spaeth GL, Donohoo P: Electron microscopy of argon laser therapy in phakic open angle glaucma. Ophthalmology 1982, 89: 198-210.

${ }^{7}$ Van Buskirk EM, Pond V, Rosenquist RC, Acott TS: Argon laser trabeculoplasty. Studies of mechanism of action. Opthalmology 1984, 91: 1005-10.

${ }^{8}$ Van der Zypen E and Fankhauser F: Ultrastructural changes of the trabecular meshwork of the monkey following irradiation with argon laser light. Graefe's Arch Clin Exp Ophthalmol 1984, 221: 249-61.

${ }^{9}$ Gorisch W and Boergen K: Laser related heat effects on blood vessels. In: Ed. Hillenkamp, Pratei and Sacchi. Lasers in Biology and Medicine. Plenum Press, New York 1980; 99-109.

${ }^{10}$ Bylsma SS, Samples JR, Acott TS, Van Buskirk EM: Trabecular cell division after argon laser trabeculoplasty. Arch Ophthalmol 1988, 106: 544-7.

${ }^{11}$ Alvarado J, Murphy C, Polansky J, Juster R: Agerelated changes in trabecular meshwork cellularity. Invest Ophthalmol Vis. Science 1981, 21: 714-27.

${ }^{12}$ Grierson I, Wang Q, McMenamin PG, Lee WR: The effects of age and antiglaucoma drugs on the meshwork cell population. Res Clin Forums 1982, 4: 69-92.

${ }^{13}$ Alvarado J, Murphy C, Juster R: Trabecular meshwork cellularity in primary open-angle glaucoma and in non-glaucomatous normals. Ophthalmology 1984, 91: 564-79.

${ }^{14}$ Grierson I: What is open angle glaucoma? Eye 1987, 1: $15-28$.

${ }^{15}$ Alexander RA, Grierson I, Church WH: The effect of argon laser trabeculoplasty upon the normal human trabecular meshwwork. Graefe's Arch Clin Exp Ophthalmol 1989, 227: 72-7.

${ }^{16}$ Acott TS, Samples JR, Bradley JM, Bacon DR, Bylsma SS, Van Buskirk EM: Trabecular repopulation by anterior trabecular meshwork cells after laser trabeculoplasty. Am J Ophthalmol 1989, 107: 1-6.

${ }^{17}$ Fankhauser F, Van der Zypen E, Kwasniewska S: Thermal effects on the trabecular meshwork induced by laser irradiation: Clinical implications deduced from ultrastructural studies on the Macaca Speciosa monkey. Trans Ophthalmol Soc UK 1986, 105: 555-61.

${ }^{18}$ Rohen JW and Lutjen-Drecoll E: Biology of the trabecular meshwork In: Lutjen-Drecoll (ed) Basic Aspects of Glaucoma Research. Schattaur, Stuttgart New York, 1982, 141-166.

${ }^{19}$ Grierson I, Day J, Unger WG, Ahmed A: Phagocytosis of latex microspheres by bovine meshwork cells in culture. Graefe's Arch Clin Exp Ophthalmol 1986, 224: 536-44. 